\title{
BMJ Open Cross-sectional study of depression and help-seeking in Uttarakhand, North India
}

\author{
Kaaren Mathias, ${ }^{1,2}$ Isabel Goicolea, ${ }^{2}$ Michelle Kermode, ${ }^{3}$ Lawrence Singh, ${ }^{4}$ \\ Rahul Shidhaye, ${ }^{5}$ Miguel San Sebastian ${ }^{2}$
}

To cite: Mathias K,

Goicolea I, Kermode M, et al. Cross-sectional study of depression and help-seeking in Uttarakhand, North India. BMJ Open 2015;5:e008992. doi:10.1136/bmjopen-2015008992

- Prepublication history for this paper is available online. To view these files please visit the journal online (http://dx.doi.org/10.1136/ bmjopen-2015-008992).

Received 6 June 2015

Revised 22 October 2015

Accepted 26 October 2015

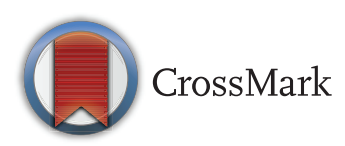

\footnotetext{
${ }^{1}$ Department of Community Health and Development, Emmanuel Hospital Association, New Delhi, India ${ }^{2}$ Department of Public Health and Clinical Medicine, Epidemiology and Global Health, Umeå University, Umeå, Sweden

${ }^{3}$ Nossal Institute for Global

Health, University of

Melbourne, Melbourne,

Victoria, Australia

${ }^{4}$ Agnes Kunze Society, Dehradun, Uttarakhand, India

${ }^{5}$ Centre for Mental Health, Public Health Foundation of India, New Delhi, India
}

Correspondence to Dr Kaaren Mathias; kaaren@eha-health.org

\section{ABSTRACT}

Objectives: This study sought to use a populationbased cross-sectional survey to describe depression prevalence, healthcare seeking and associations with socioeconomic determinants in a district in North India.

Setting: This study was conducted in Sahaspur and Raipur, administrative blocks of Dehradun district, Uttarakhand, in July 2014.

Participants: A population-based sample of 960 people over the age of 18 years was selected in 30 randomised clusters after being stratified by rural:urban census ratios.

Primary outcome measures: The survey used a validated screening tool, Patient Health Questionnaire, to identify people with depression, and collected information regarding socioeconomic variables and help-seeking behaviours. Depression prevalence and health seeking behaviours were calculated, and multivariable logistic regression was used to assess associations between risk factors and depression.

Results: Prevalence of depression was 6\% (58/960), with a further $3.9 \%$ (37/960) describing a depressive episode of over 2 weeks in the past 12 months.

Statistically significant adjusted OR for depression of more than 2 were found for people who were illiterate, classified as Scheduled Caste/Tribe or Other Backward Castes, living in temporary material housing and who had recently taken a loan. While over three quarters of people with depression $(79 \%)$ had attended a private or government general medical practitioner in the past 3 months, none had received talking therapy $(100 \%$ treatment gap) and two people (3.3\%) had been prescribed antidepressants.

Conclusions: There are clear associations between social, educational and economic disadvantage and depression in this population. Strategies that address the social determinants of depression, such as education, social exclusion, financial protection and affordable housing for all are indicated. To address the large treatment gap in Uttarakhand, we must ensure access to primary and secondary mental health providers who can recognise and appropriately manage depression.

\section{INTRODUCTION}

Depression, the most common mental disorder (CMD), accounts for $9.7 \%$ years lived with disability in the 2010 Global Burden of

\section{Strengths and limitations of this study}

- Data derived from this community-based crosssectional randomly selected sample shows that over $6 \%$ of adults in Dehradun district, Uttarakhand, are depressed.

- Risk of depression is two to three times higher for people who have had very little schooling, who live in poor housing, who have taken a recent loan and who identify as belonging to a Scheduled Caste or Tribe (Scheduled Castes are typically the groups most socially excluded in Indian society; they are also referred to as Dalits or Harijans).

- There is a large gap in access to effective care: $0 \%$ had received talking therapy and only $3.3 \%$ of people with depression had been prescribed antidepressants, although the majority had attended a primary care provider in the previous 3 months.

- A limitation of this study is that the estimate of prevalence is through a screening tool rather than definitive diagnosis by a psychiatrist. The cross-sectional design cannot indicate causation and the survey covered only one district of Uttarakhand state, which may limit generalisability.

Disease study. ${ }^{1}$ Depression-related disability, compounded by lack of access to care, impacts on social and physical health. Prevalence estimates of depression in India have varied widely depending on the assessment tools used and the community's sociodemographic profile. ${ }^{2}{ }^{3}$ Ganguli $^{3}$ reviewed 15 studies of psychiatric morbidity, and found a mean prevalence of $3.4 \%$. Reddy and Chandrasekhar's ${ }^{4}$ meta-analysis of 33572 participants described prevalence at $8.9 \%$, with urban rates nearly double rural rates. Other studies in South Asia have shown even higher rates, for example, $15.1 \%$ in urban South India ${ }^{5}$ and $45.9 \%$ in urban Pakistan. ${ }^{6}$

Robust evidence from India and other low and middle income countries (LMIC) links socioeconomic deprivation with increased 
risk of depression. ${ }^{7-9}$ Other groups shown to be at higher risk for depression in India are women, the elderly, urban dwellers and people who are divorced or widowed. $^{3-5} 79$

India's highly inequitable distribution of mental health resources means at least $90 \%$ of people with mental disorders (PWMDs) are undiagnosed and untreated. ${ }^{10}$ There are also huge disparities in access to mental health services particularly for people in rural areas. ${ }^{4}$ Barriers to help-seeking include unavailability of services, poor quality of the majority of existing services, lack of knowledge about mental illness, and fear of stigma and discrimination. ${ }^{11}{ }^{12}$ People with depression in India report distress primarily as unexplained somatic symptoms, and usually seek help from primary care rather than specialist mental healthcare providers. ${ }^{13} 14$ Simultaneously, conceptual understandings of depression are not well captured by current disease classification systems ${ }^{15}$ and ongoing reflection is needed about when mental distress becomes a disorder.

There is an urgent need to understand the burden of disease in areas where prevalence studies have never before been conducted, ${ }^{16}$ and to understand the pathways to care currently utilised. ${ }^{17}$ Few studies of depression in India have examined the associations between depression and social determinants of health, and almost none have considered the association between depression and caste. ${ }^{2-5} 7$ There are very few studies of depression prevalence in the Hindi-speaking belt with existing studies predominantly from Southern and Eastern India. ${ }^{2-5} 918$ We could find no study on the prevalence or epidemiology of depression in Uttarakhand, a state with a population of 10 million. This study describes the prevalence of depression, sociodemographic associations and the help-seeking behaviours of people with depression.

\section{METHODS}

Setting

This study was conducted in two blocks (administrative unit with up to 200000 inhabitants) in Dehradun district, Uttarakhand, as part of the baseline survey for Burans, a community mental health partnership project with the Emmanuel Hospital Association (http://www. eha-health.org) and the Uttarakhand Community Health Global Network (http://www.chgnukc.org). Burans is directed by the first author. Housing is an important indicator of socioeconomic status in this setting. Permanent materials housing refers to housing that is predominantly made with a sealed floor, walls of a solid material (eg, brick) and a corrugated iron roof. Temporary materials housing refers to housing with a dirt floor and/or walls and roofing constructed from straw/tarpaulin or plastic sheets. The national District Mental Health Plan had not been implemented in Uttarakhand at the time of this survey. During the survey period, there were two government psychiatrists and no government psychologists, with 10-15 private psychiatrists and psychologists across Uttarakhand. Government primary care services did not generally treat PWMDs, nor did they supply essential medicines such as antidepressants.

\section{Sample selection}

We selected 960 people from 30 randomised clusters. Cluster sampling was conducted in three phases: (1) ward or panchayat (administrative unit, approximately 5000 people); (2) household and (3) participant. We used STATA $^{19}$ to calculate a sample size of $n=480$ (estimating depression prevalence at $10 \%$ (based on other Indian population-based studies) ${ }^{3}{ }^{5}$ ) and a sampling frame of 235000 (population of 2 blocks of Dehradun district), 30 clusters and 95\% CIs. To account for the effects of clustering, we allowed a design effect of 2, giving a final total of 960 persons.

Clusters were stratified based on rural:urban ratios in the district's 2011 census, ${ }^{20}$ to require 21 urban and 9 rural clusters. These were selected by random number generation from the publicly available list of census panchayats and wards. To select at household level, the surveying team walked to the centre of the community, and spun a pen to ascertain which direction to start. Every 6 th house on the right was surveyed, and at each junction, roads/ alleys on the right were followed. If no one was present at a selected household, the team revisited that household later. If no one was present on the second visit, the first house to the right was selected. Only one person from each household was surveyed. Generally, male field staff surveyed male respondents, and female staff surveyed female respondents. Once the requisite $50 \%$ of female participants was reached, all survey staff surveyed male respondents. Inclusion criteria were that participants should be occupants of a household, 18 years or older, and able to comprehend and respond to a survey.

\section{Data collection}

Project Burans field staff, all from the district of Dehradun (equal numbers of males and females), collected data in July and August 2014. All were trained in sampling strategy, use of the survey tool, data recording and management, and ethical research, and were supervised and supported by KM.

A comprehensive survey tool was translated to Hindi, back translated to English and piloted extensively by the PRIME team in Madhya Pradesh. ${ }^{21}$ The survey was interviewer administered in Hindi. Components reported in this paper are:

- Sociodemographic information including indicators of housing quality, indebtedness, caste, marital status, highest education level attained and employment status, adapted from the Indian version of the demographic and health surveys. ${ }^{22}$ Proxy measures of socioeconomic status included housing quality, educational status and employment status. We used norms of the Government of India to assess housing 
quality where permanent material housing referred to classifications of 'Pukka' and 'Semi-kaccha' and temporary material housing referred to the 'Kaccha' classification. $^{23}$

- General health help-seeking behaviour and health service utilisation (including 'Have you visited any health facility/provider in the last 3 months?') ${ }^{23}$

- Adapted questions from the Client Service Receipt Inventory ${ }^{24}$ used to ask participants about recent inpatient and outpatient services, including type of provider (government primary provider, government secondary provider, private medical sector or charity provider, mental health provider, traditional or religious healer).

- Talking therapy or medication prescription received (generic or brand name, dose, duration and source).

- Patient Health Questionnaire (PHQ9) - a self-report screening tool assessing clinical depression (validated internationally and in India). ${ }^{25-27}$ This questionnaire comprises nine items, each is scored 0 to 3 , which thus yields a severity score from 0 and 27 . Response categories, based on frequency of a particular symptom over the last 2 weeks are scored $0,1,2$ and 3 , for 'not at all', 'several days', 'more than half the days', and 'nearly every day', respectively. In our study, a person with a PHQ9 score of 10 or higher was assessed as having at least moderate depression, in line with international norms for PHQ9. ${ }^{27}$

- Mental health service seeking behaviour among those screening positive for depression using the same codes as for general health seeking behaviour.

At census enumeration and on birth registration, Indians of Jain, Sikh and Hindu religion must identify themselves as General Caste, Other Backward Classes (OBC) or a member of a Scheduled Tribe/Caste (SC/ ST), based on the identity of their parents. ${ }^{28}$ In the Dehradun area, the vast majority of Muslims are included under the OBC category. Christians and Buddhists are classified into the General Caste category.

\section{Analysis}

Survey data were analysed using STATA V.13.1. ${ }^{19}$ Open text was translated into English, grouped thematically and coded. Univariable logistic regression analysis was performed using all relevant socioeconomic variables and significant variables $(p<0.05)$ were considered in the multivariable logistic regression analysis. The dependent variable was dichotomised: no depression $=0$, depression $=1$. The original interpretation defined a total score of 5-9 as mild depression, and above 9 as moderate-to-severe depression. In this study, we designated all respondents with a score of greater than 9 as being 'depressed'. $\chi^{2}$ Test was used in analysis of tables 1 and 2. A $p$ value $<0.05$ was considered statistically significant.

All participants gave written consent to participate in the study, and respondents who screened positively for depression were given information on depression, and advised on health services and other sources of help.

\section{RESULTS}

Within two contact attempts, 958 of 960 selected households were successfully surveyed and the remaining two were surveyed on the third visit. Survey participants' demographic characteristics are summarised in table 3. Nearly one-quarter were lowest caste or had tribal status (SC and ST). Thirty-five per cent had six or fewer years of schooling.

The sampled survey population had a mean age of 39.4 years and a median age of 37.5 years. The mean period of education completed was 8.0 years and the median was 9 years. The sample differs significantly from the wider Uttarakhand population ${ }^{20}$ by greater representation of middle-aged people classified as SC/ST and unschooled people.

Table 4 summarises the prevalence of depression, sociodemographic characteristics and their association with the PHQ9 depression score with crude and adjusted ORs. Depression prevalence was $6 \%$. The significant association with increased risk of depression in women disappeared when other confounding factors such as educational status and economic deprivation were accounted for. People in their middle years had a slightly higher risk of depression than those under 30 years and over 50 years of age. People who lived in a house made of temporary materials were almost twice as

\begin{tabular}{|c|c|c|c|c|}
\hline & $\begin{array}{l}\text { Not depressed } \\
\text { N (\%) }\end{array}$ & $\begin{array}{l}\text { Depressed } \\
\text { N (\%) }\end{array}$ & $\begin{array}{l}\text { No depression in last } \\
12 \text { months, } N(\%)\end{array}$ & $\begin{array}{l}\text { Depression in last } \\
12 \text { months, } N(\%)\end{array}$ \\
\hline $\begin{array}{l}\text { Visited outpatient health provider in } \\
\text { last } 3 \text { months }\end{array}$ & 138 (15.3) & $45(77.6)^{*}$ & 120 (13.8) & $63(68.5)^{*}$ \\
\hline $\begin{array}{l}\text { No visit to outpatient health provider } \\
\text { in last } 3 \text { months }\end{array}$ & 764 (84.7) & $13(22.4)^{\star}$ & 748 (86.2) & $29(31.5)^{\star}$ \\
\hline $\begin{array}{l}\text { Hospital admission in last } \\
12 \text { months }\end{array}$ & $41(4.5)$ & $15(25.8)^{\star}$ & $35(4.0)$ & $21(22.8)^{\star}$ \\
\hline $\begin{array}{l}\text { No hospital admission in last } \\
12 \text { months }\end{array}$ & $860(95.5)$ & $43(74.2)^{\star}$ & $832(96.0)$ & $71(77.2)^{\star}$ \\
\hline
\end{tabular}


Table 2 Type of health providers visited in the last 3 months

\begin{tabular}{|c|c|c|}
\hline $\begin{array}{l}\text { Type of outpatient } \\
\text { provider }\end{array}$ & $\begin{array}{l}\text { Not depressed } \\
\text { N (\%) }\end{array}$ & $\begin{array}{l}\text { Depressed } \\
\text { N (\%) }\end{array}$ \\
\hline $\begin{array}{l}\text { Government provider } \\
(\mathrm{CHC} \text { or } \mathrm{PHC})\end{array}$ & $54(40.3)$ & $22(47.8)$ \\
\hline $\begin{array}{l}\text { Community level } \\
\text { government provider } \\
\text { (PHC or ANM) }\end{array}$ & $7(5.0)$ & $2(4.3)$ \\
\hline $\begin{array}{l}\text { Private health } \\
\text { provider }\end{array}$ & $70(52.2)$ & $18(41.8)$ \\
\hline $\begin{array}{l}\text { Mental health } \\
\text { provider }\end{array}$ & $1(0.7)$ & $1(2.3)$ \\
\hline Traditional healer & $6(4.4)$ & $2(4.3)$ \\
\hline Total & $\begin{array}{l}138(16.2 \% \text { of } \\
\text { total } \\
\text { non-depressed })\end{array}$ & $\begin{array}{l}45(79 \% \text { of } \\
\text { total } \\
\text { depressed })\end{array}$ \\
\hline $\begin{array}{l}\text { Prescribed } \\
\text { antidepressants }\end{array}$ & $1(0.7)$ & $2(4.3)$ \\
\hline $\begin{array}{l}\text { Supported with } \\
\text { talking therapy }\end{array}$ & 0 & 0 \\
\hline
\end{tabular}

ANM, Auxiliary Nurse Midwife; $\mathrm{CHC}$, community health centres;

PHC, primary health centres.

likely to be classified as depressed, and those who had taken a loan recently were three times more likely. Those classified as SC or ST had three times the odds of being classified as depressed. A dose-response relationship was seen in educational status, with risk of depression increasing with decreasing years of completed schooling.

Table 1 shows the help-seeking behaviours of those screened as depressed (using PHQ9) or who selfreported a $>2$ week episode of depression in the last 12 months. People with depression were five times more likely to have visited outpatient or inpatient providers than people without depression. Separate analysis showed that all women, with and without depression, were significantly more likely than men to have visited a health provider in the prior 3 months.

Table 2 shows the type of health provider visited by the 183 people who made an outpatient visit in the previous 3 month. Depressed people, compared to nondepressed, consult health providers significantly more, and are far more likely to visit general health providers than to visit mental health services. Only two people had visited a mental health service provider in the previous 3 months. No one with depression had received talking therapy. Two people with depression at the time of the survey had been prescribed antidepressants through private practitioners, while one respondent who screened negatively for depression had been prescribed antidepressants.

\section{DISCUSSION}

This study shows a $6 \%$ prevalence of depression using a depression screening tool in a randomly sampled

Table 3 Demographic characteristics of participants

\begin{tabular}{|c|c|c|c|}
\hline Variables & Female N (\%) & Male N (\%) & Total N (\%) \\
\hline Total & 480 & 480 & 960 \\
\hline \multicolumn{4}{|l|}{ Age (years) } \\
\hline $18-29$ & $159(33.1)$ & $121(25.2)$ & $280(29.2)$ \\
\hline 30-39 & $145(30.2)$ & $101(21.0)$ & $246(25.6)$ \\
\hline $40-49$ & $100(20.8)$ & $101(21.0)$ & 201 (20.9) \\
\hline $50-59$ & $44(9.2)$ & $80(16.7)$ & $124(12.9)$ \\
\hline $60+$ & $32(6.7)$ & 77 (16.1) & 109 (11.2) \\
\hline \multicolumn{4}{|l|}{ Marital status } \\
\hline Married & $366(50.4)$ & $360(49.6)$ & $726(75.6)$ \\
\hline Divorced/separated & $48(10.0)$ & $13(2.7)$ & $61(6.4)$ \\
\hline Single & 66 (13.7) & 107 (22.3) & $173(18.0)$ \\
\hline \multicolumn{4}{|l|}{ Rural/urban } \\
\hline Rural & $145(30.2)$ & $143(29.8)$ & $288(30.0)$ \\
\hline Urban & 335 (69.8) & 337 (70.2) & $672(70.0)$ \\
\hline \multicolumn{4}{|l|}{ Education } \\
\hline None/incomplete primary & 109 (22.7) & $51(10.6)$ & $160(16.7)$ \\
\hline Primary completion & $88(18.3)$ & $90(18.7)$ & $178(18.5)$ \\
\hline Secondary completion & 199 (41.5) & $273(56.9)$ & 472 (49.2) \\
\hline Graduate & $84(17.5)$ & $66(13.7)$ & $150(15.6)$ \\
\hline \multicolumn{4}{|l|}{ Religion } \\
\hline Hindu & 401 (83.5) & 308 (82.9) & 799 (83.2) \\
\hline Muslim & $71(14.8)$ & $70(14.6)$ & $141(14.7)$ \\
\hline Other & $8(1.7)$ & $11(2.5)$ & $19(2.1)$ \\
\hline \multicolumn{4}{|l|}{ Caste } \\
\hline Scheduled Caste/Tribe & $122(25.4)$ & $116(24.2)$ & $238(24.8)$ \\
\hline Other Backward Caste & $74(15.4)$ & $73(15.2)$ & 147 (15.3) \\
\hline General & $284(59.2)$ & $291(60.6)$ & 575 (59.9) \\
\hline
\end{tabular}


Table 4 Prevalence and risk factors for depression in Dehradun district, Uttarakhand

\begin{tabular}{|c|c|c|c|c|c|c|c|}
\hline Descriptive variable & $\begin{array}{l}\text { Non-depressed } \\
\mathrm{N}(\%)\end{array}$ & $\begin{array}{l}\text { Depressed } \\
\text { N (\%) }\end{array}$ & p Value & $\begin{array}{l}\text { Crude } \\
\text { OR }\end{array}$ & $95 \% \mathrm{Cl}$ & Adjusted OR & $95 \% \mathrm{Cl}$ \\
\hline Total & $902(94.0)$ & $58(6.0)$ & & & & & \\
\hline \multicolumn{8}{|l|}{ Sex } \\
\hline Male & $460(95.8)$ & $20(4.2)$ & & 1.0 & & & \\
\hline Female & $442(92.1)$ & 38 (7.9) & $<0.001$ & 2.0 & 1.1 to $3.5^{\star}$ & 0.6 & 0.3 to 1.2 \\
\hline \multicolumn{8}{|l|}{ Age (years) } \\
\hline $18-29$ & $270(96.4)$ & $10(3.6)$ & & 1.0 & & & \\
\hline 30-39 & $230(93.5)$ & $16(6.5)$ & & 1.9 & 0.8 to 4.2 & & \\
\hline $40-49$ & $183(91.0)$ & $18(7.0)$ & & $2.7^{*}$ & 1.2 to $5.9^{*}$ & & \\
\hline $50-59$ & $116(93.5)$ & $8(6.5)$ & & 1.9 & 0.7 to 4.8 & & \\
\hline 60 and over & $103(94.5)$ & $6(5.5)$ & & 1.6 & 0.6 to 4.4 & & \\
\hline \multicolumn{8}{|l|}{ Caste } \\
\hline General & $557(96.9)$ & $18(3.1)$ & & 1.0 & & & \\
\hline OBC & 137 (93.2) & $10(6.8)$ & & $2.3^{*}$ & 1.0 to $5.0^{\star}$ & 2.1 & 0.9 to 4.8 \\
\hline SC/ST & $208(87.4)$ & $30(12.6)$ & $<0.001$ & $4.5^{\star}$ & 2.4 to $8.2^{\star}$ & $3.2^{\star}$ & 1.7 to $6.2^{\star}$ \\
\hline \multicolumn{8}{|l|}{ Religion } \\
\hline Hindu & $755(94.5)$ & $44(5.5)$ & & 1.0 & & & \\
\hline Non-hindu & 147 (91.3) & $14(8.7)$ & & 1.6 & 0.9 to 3.0 & & \\
\hline \multicolumn{8}{|l|}{ House type } \\
\hline Permanent & $760(96.0)$ & $32(4.0)$ & & 1.0 & & & \\
\hline Temporary & $142(84.5)$ & $26(15.5)$ & $<0.001$ & $3.3^{*}$ & 1.9 to $5.7^{*}$ & $1.9^{\star}$ & 1.0 to $3.5^{\star}$ \\
\hline \multicolumn{8}{|l|}{ Loan in last 6 months } \\
\hline No & 845 (95.1) & $44(4.9)$ & & 1.0 & & & \\
\hline Yes & 57 (80.3) & $14(19.7)$ & $<0.001$ & $4.7^{*}$ & 2.4 to $9.1^{*}$ & $3.0^{*}$ & 1.4 to $6.2^{*}$ \\
\hline \multicolumn{8}{|l|}{ Education status } \\
\hline Unschooled & $135(84.4)$ & $25(15.6)$ & & 6.8 & 2.3 to 19.9 & $3.7^{\star}$ & 1.2 to $12.0^{*}$ \\
\hline Primary & $168(94.4)$ & $10(5.6)$ & & 2.2 & 0.7 to 7.0 & 2.0 & 0.6 to 7.1 \\
\hline Secondary & $453(96.0)$ & $19(4.0)$ & & 1.5 & 0.5 to 4.6 & 1.5 & 0.5 to 4.7 \\
\hline Graduate & 146 (97.3) & $4(2.7)$ & $<0.001$ & 1.0 & & & \\
\hline \multicolumn{8}{|l|}{ Employment } \\
\hline Professional/military & 102 (92.7) & $8(7.3)$ & & 1.0 & & & \\
\hline Self-employed & $231(97.5)$ & $6(2.5)$ & & $0.3^{*}$ & 0.1 to $0.98^{*}$ & & \\
\hline Unskilled manual & 341 (93.9) & $22(6.1)$ & & 0.8 & 0.4 to 1.9 & & \\
\hline Unemployed & 228 (91.2) & $22(8.8)$ & $<0.05$ & 1.2 & 0.5 to 2.9 & & \\
\hline
\end{tabular}

population in Dehradun district, Uttarakhand. Some studies suggest prevalence in India may be higher. ${ }^{4} 629$ In this study, no one had received talking therapy, indicating a treatment gap of $100 \%$ for the recommended first-line treatment of mild or moderate depression. ${ }^{30}$ Antidepressants are the recommended second-line treatment for depression, ${ }^{30}$ and although we cannot ascertain how many of the $96.3 \%$ people would have benefitted from these medicines, it is likely this also represents a large treatment gap. Extrapolating these findings to Uttarakhand's adult population of 6.6 million, ${ }^{20}$ we estimate 400000 people may have depression, of whom just 4000 may have access to antidepressants and almost no one is likely to have access to talking therapy-a huge mismatch between disease burden and health service provision.

This study shows much greater risk of depression for three groups-the poorest (those in houses constructed from temporary materials and who had taken a recent loan); those who self-identify as OBC, SC or ST; and the unschooled/illiterate. Each of these associations has an adjusted OR for depression of at least twice that of their reference group. A systematic literature review in LMIC shows depression to be strongly associated with socioeconomic deprivation, ${ }^{8}$ supporting the WHO Commission on the Social Determinants of health concept of mediating pathways that link poverty with lack of access to political recognition and economic power. $^{31}$ Other Indian studies also suggest socioeconomic factors as the key determinants of depression. ${ }^{45} 7$ Similar to a 'canary in a coal mine', depression may be conceptualised as an indicator of social inequity and vulnerability.

Although mental health has been linked with socioeconomic disadvantage and social exclusion, caste, a key indicator of social identity in India, has not been well investigated as a risk factor. One Indian study of the prevalence of CMDs among rural women found no 
association with caste. ${ }^{7}$ A further study in rural Nepal found that caste-based disparities in mental health are mediated by poverty, lack of social support and stressful life events. ${ }^{32}$ However, Sen's ${ }^{33}$ capabilities approach emphasises rights and command over goods, recognises the relational roots of deprivation, and underscores the importance of agency and participation for genuine social inclusion. This view is supported by others describing psychosocial and biological pathways between social exclusion and health. ${ }^{34}{ }^{35}$ It seems likely, therefore, that social exclusion, marked by caste, increases the risk of depression.

For decades, Indian national policy has sought to legislatively benefit SC and ST, for example, the Reservation in Admission Act $2006^{36}$ and the Protection of Civil Rights Act 1955. ${ }^{37}$ Despite such measures, and even after controlling for socioeconomic status (years of schooling, housing quality, indebtedness), members of SC and ST groups in this study had more than twice the risk for depression compared to the General Caste. It is likely that persisting social structures of exclusion and discrimination are more penetrating than legislation, and that they continue to create relative deprivation, reduce agency and exclude people.

Associations between poverty and CMDs in LMIC countries and in India are well described. ${ }^{13}$ This study found that depression prevalence among people who had taken a recent loan was thrice that of those who had not. Two other studies from India show indebtedness as a risk factor for primary care attenders diagnosed with a CMD. ${ }^{13} 38$ Links between personal debt and mental health are well described, ${ }^{13} 3940$ although there have been no prospective longitudinal studies to show the direction of association. Possible mediating pathways between depression and indebtedness include shame, stress of financial insecurity ${ }^{39}$ and less capacity to earn income due to depression.

Another strong risk factor for depression in this study is educational status. People who had not completed primary schooling had almost four times greater risk after controlling for caste, housing, indebtedness and employment status. Our results show a striking doseresponse relationship: increasing years of education provide increasing protection. A meta-analysis examining the associations between socioeconomic inequality and depression also reported this finding. ${ }^{41}$ Education status has been described in India and other LMICs as predictive of mental health outcomes. ${ }^{41-43}$ Social consequences of low levels of education are multiple and move beyond schooling as a marker of deprivation, including reduced opportunity to access resources, and to develop protective social and cognitive skills, and increased risk for mental distress. Reverse causality is unlikely to be a factor, as primary education occurs at an age when CMDs are uncommon.

Although people with depression were seeking care, they were not getting the help they needed. This study shows that most people with depression had attended primary healthcare providers in the previous 3 months, in the Government as well as in the private sectors. The somatisation of depression among people with depression in Asian cultures, particularly women, is well described. ${ }^{44}$ Many health providers are unable to recognise somatisation, leading to excessive, costly and often inappropriate investigation and treatment. Also noteworthy is that only eight people in this sample reported consultations with traditional healers. Others have described up to two-thirds of people with severe mental disorders in India seeking help from traditional healers during their illness. ${ }^{17}$ The strong association between somatoform disorders and CMDs highlights the need for primary care providers to be equipped with knowledge and skills to recognise and manage the diverse presentations of CMDs. ${ }^{14} 44$

This study shows depression as a community outcome of macroeconomic and political decisions that can lead to mental distress and suffering for communities as well as for individuals. There are several important implications for policy and practice. Foremost, since social determinants of health almost certainly contribute to depression, macropolicies that address determinants such as poor housing, caste, indebtedness and low education, will also reduce depression disease burden. Policies to improve mental health must seek to reduce poverty and social exclusion ${ }^{45}$ and actively include communities.

Second, action is urgently required to increase provision of mental health services and medicines, as strongly advocated by the Lancet mental health group and series. ${ }^{29} 45$ However, perhaps more importantly, primary care doctors in India, being the healthcare providers most commonly consulted by people with depression, ${ }^{9} 14$ need the knowledge, skills and perception to recognise the diverse presentations of CMDs such as depression and anxiety, and to treat them appropriately with both talking and pharmaceutical therapies.

\section{Methodological considerations}

A major strength of this study is that its data are from a randomly selected population covering rural, semiurban and urban populations typical for a district in North India, in 2014. Multivariable analysis ensured that potentially confounding factors were considered. However, there are some methodological limitations: self-reported measures may risk recall bias and cultural factors. PHQ9 is a screening-not diagnostic-tool constructed using a definition of depression (Diagnostic and Statistical Manual of Mental Disorders, Fifth Edition and International Classification of Diseases 10th Revision); it has been critiqued as being over simplistic and risks labelling components of normal human experience as a disorder. ${ }^{15}$ This cross-sectional study cannot attribute causality to apparent risk factors. The survey tool excluded three key risk factors-stressful life events, chronic illness and disability. The lower than expected prevalence of depression (6\%) may be related to the 
emphasis in the PHQ9 on cognitive manifestations of depression possibly missing the somatic features common in Asian cultures. ${ }^{44}$

\section{CONCLUSION}

Depression in Dehradun district of Uttarakhand, with a prevalence of at least $6 \%$, is two or three times more common among people who are economically deprived, those who are part of the most excluded caste group or those who have had little education. Almost no one with depression accesses effective primary or secondary mental healthcare. Social policy and health service responses must urgently address this preventable and treatable disease burden and treatment gap. CMDs are indeed common, and disproportionately affect the most vulnerable.

Acknowledgements The authors would like to thank the hard-working Burans teams of OPEN, LCH, Sneha and HOPE for surveying/data collection in a very wet monsoon. They also thank Kezia Chand, Gabriella Ailstock and Suraj Chetri for their support in data quality, and Linda Seefeldt for support with Stata, as well as Rajan Arora, R Srivatsan, Jeph Mathias and Prachin Ghodajkar for their suggestions on drafts of the paper.

Contributors KM conceived of the study and main design, performed data collection and data analysis, and wrote the first draft. IG and MK contributed to design and editing of the first and subsequent drafts. LS supported data collection and analysis. RS contributed to the literature review and subsequent drafts. MSS supported study design, analysis and overview of the whole paper

Funding This research was partially funded by the Umeå Centre for Global Health Research, funded by FAS, the Swedish Council for Working Life and Social Research, Grant number 2006-1512.

Competing interests None declared.

Patient consent Obtained.

Ethics approval Ethics approval was obtained from the Emmanuel Hospital Association Institutional Review Board of Ethics in New Delhi, in April 2014.

Provenance and peer review Not commissioned; externally peer reviewed.

Data sharing statement No additional data are available.

Open Access This is an Open Access article distributed in accordance with the Creative Commons Attribution Non Commercial (CC BY-NC 4.0) license, which permits others to distribute, remix, adapt, build upon this work noncommercially, and license their derivative works on different terms, provided the original work is properly cited and the use is non-commercial. See: http:// creativecommons.org/licenses/by-nc/4.0/

\section{REFERENCES}

1. Whiteford HA, Degenhardt L, Rehm J, et al. Global burden of disease attributable to mental and substance use disorders: findings from the Global Burden of Disease Study 2010. Lancet 2013;382:1575-86.

2. Math S, Chandrashekar C, Bhugra D. Psychiatric epidemiology in India. Indian J Med Res 2007;126:183-92.

3. Ganguli $\mathrm{H}$. Epidemiological findings on prevalence of mental disorders in India. Indian J Psychiatr 2000;42:14-20.

4. Reddy VM, Chandrashekar C. Prevalence of mental and behavioural disorders in India: a meta-analysis. Indian J Psychiatry 1998:40:149.

5. Poongothai S, Pradeepa R, Ganesan A, et al. Prevalence of depression in a large urban South Indian population-the Chennai Urban Rural Epidemiology Study (CURES-70). PLoS ONE 2009;4: e7185

6. Muhammad Gadit A, Mugford G. Prevalence of depression among households in three capital cities of Pakistan: need to revise the mental health policy. PLOS ONE 2007;2:e209.
7. Shidhaye R, Patel V. Association of socio-economic, gender and health factors with common mental disorders in women: a population-based study of 5703 married rural women in India. Int $J$ Epidemiol 2010;39:1510-21.

8. Lund C, Breen A, Flisher AJ, et al. Poverty and common mental disorders in low and middle income countries: a systematic review. Soc Sci Med 2010;71:517-28.

9. Grover S, Dutt A, Avasthi A. An overview of Indian research in depression. Indian J Psychiatry 2010;52(Suppl 1):S178-88.

10. World Health Organisation. Mental health atlas 2011. Geneva: WHO, 2011.

11. Raguram R, Weiss MG, Channabasavanna SM, et al. Stigma, depression, and somatization in South India. Am J Psychiatry 1996;153:1043-9.

12. Kermode $\mathrm{M}$, Bowen $\mathrm{K}$, Arole $\mathrm{S}$, et al. Community beliefs about treatments and outcomes of mental disorders: a mental health literacy survey in a rural area of Maharashtra, India. Public Health 2009;123:476-83.

13. Pothen M, Kuruvilla A, Philip K, et al. Common mental disorders among primary care attenders in Vellore, South India: nature, prevalence and risk factors. Int J Soc Psychiatry 2003;49:119-25.

14. Pattanayak RD, Sagar R. Depressive disorders in Indian context: a review and clinical update for physicians. J Assoc Physicians India 2014;62:827-32.

15. Jacob K, Patel V. Classification of mental disorders: a global mental health perspective. Lancet 2014;383:1433-5.

16. De Silva MJ. Impact evaluations of mental health programmes: the missing piece in global mental health. J Epidemiol Community Health 2015;69:405-7.

17. Lahariya C, Singhal S, Gupta S, et al. Pathway of care among psychiatric patients attending a mental health institution in centra India. Indian J Psychiatry 2010;52:333-8.

18. Nandi DN, Banerjee G, Mukherjee SP, et al. Psychiatric morbidity of a rural Indian community. Changes over a 20 -year interval. $\mathrm{Br} \mathrm{J}$ Psychiatry 2000;176:351-6.

19. STATA Corp LP. STATA 13.1. Texas, USA: STATA Corp, 2013.

20. Government of India. Census 2011 Secondary Census 2011. 2011. http://www.census2011.co.in/census

21. PRIME. Programme for Improving Mental Health Care. Secondary Programme for Improving Mental Health Care. 2013. http://www. centreforglobalmentalhealth.org/projects-research/prime-programmeimproving-mental-health-care

22. International Institute for Population Sciences MI. Indian National Family Health Survey (NFHS-3) 2005-6. Mumbai: International Institute for Population Sciences, 2007.

23. Anant T, Das S. Housing report. 44th edn. New Delhi: Housing [Internet], 2011.

24. Beecham JK, Knapp MRJ. Costing psychiatric interventions. In Thornicroft G, ed. Measuring mental health needs. London: Gaskell, 2001:200-24.

25. Poongothai S, Pradeepa R, Ganesan A, et al. Reliability and validity of a modified PHQ9 item inventory (PHQ12) as a screening instrument for assesing depression in Asian Indians (CURES-65). J Assoc Physicians India 2009;57:147-52.

26. Kochhar PH, Rajadhyaksha SS, Suvarna VR. Translation and validation of brief patient health questionnaire against DSM IV as a tool to diagnose major depressive disorder in Indian patients. J Postgrad Med 2007;53:102-7.

27. Kroenke K, Spitzer R, Williams J. The PHQ-9: validity of a brief depression severity measure. J Gen Intern Med 2001;16:606-13.

28. Mukherjee S. Conceptualisation and classification of caste and tribe by the Census of India. J Anthropol Surv India 2013;62:805-20.

29. Prince M, Patel V, Saxena S, et al. No health without mental health. Lancet 2007;370:859-77.

30. NICE. Depression: the treatment and management of depression in adults (update). NICE Clinical Guideline 90. London: NICE, 2011.

31. World Health Organisation. Social commission on the social determinants of health. Geneva: WHO, 2006.

32. Kohrt BA, Speckman RA, Kunz RD, et al. Culture in psychiatric epidemiology: using ethnography and multiple mediator models to assess the relationship of caste with depression and anxiety in Nepal. Ann Hum Biol 2009;36:261-80

33. Sen AK. Social exclusion: Concept, application, and scrutiny. Manila: Office of Environment and Social Development, Asian Development Bank, 2000.

34. Slavich GM, O'Donovan A, Epel ES, et al. Black sheep get the blues: a psychobiological model of social rejection and depression. Neurosci Biobehav Rev 2010;35:39-45.

35. Ahmed AT, Mohammed SA, Williams DR. Racial discrimination \& health: pathways \& evidence. Indian J Med Res 2007;126:318-27. 
36. Development MoHR. Central educational institutions (reservation in admission) act. India: Ministry of Human Resource Development, 2006.

37. Empowerment MoSJa. Protection of Civil Right Act. PCR 1955. India, 1955.

38. Patel V, Pereira J, Coutinho L, et al. Poverty, psychological disorder and disability in primary care attenders in Goa, India. Br J Psychiatry 1998;172:533-6.

39. Reading R, Reynolds S. Debt, social disadvantage and maternal depression. Soc Sci Med 2001;53:441-53.

40. Richardson T, Elliott P, Roberts R. The relationship between personal unsecured debt and mental and physical health: a systematic review and meta-analysis. Clin Psychol Rev 2013;33:1148-62.
41. Lorant V, Deliege D, Eaton W, et al. Socioeconomic inequalities in depression: a meta-analysis. Am J Epidemiol 2003;157:98-112.

42. Chatterjee S, Pillai A, Jain S, et al. Outcomes of people with psychotic disorders in a community-based rehabilitation programme in rural India. Br J Psychiatry 2009;195:433-9.

43. Patel V, Kleinman A. Poverty and common mental disorders in developing countries. Bull World Health Organ 2003;81:609-15.

44. Shidhaye R, Mendenhall E, Sumathipala K, et al. Association of somatoform disorders with anxiety and depression in women in low and middle income countries: a systematic review. Int Rev Psychiatry 2013;25:65-76.

45. Lund C, De Silva M, Plagerson S, et al. Poverty and mental disorders: breaking the cycle in low-income and middle-income countries. Lancet 2011;378:1502-14. 